\title{
Médiévales
}

Langues, Textes, Histoire

74 | printemps 2018

Chanter la Croisade albigeoise

\section{La Chanson de la Croisade albigeoise}

\section{Katy Bernard}

\section{(2) OpenEdition}

\section{Journals}

Édition électronique

URL : https://journals.openedition.org/medievales/8315

DOI : $10.4000 /$ medievales. 8315

ISSN : 1777-5892

\section{Éditeur}

Presses universitaires de Vincennes

\section{Édition imprimée}

Date de publication : 15 juillet 2018

Pagination : 5-7

ISBN : 978-2-84292-837-7

ISSN : 0751-2708

\section{Référence électronique}

Katy Bernard, «La Chanson de la Croisade albigeoise », Médiévales [En ligne], 74 | printemps 2018, mis en ligne le 15 juillet 2018, consulté le 24 avril 2022. URL : http://journals.openedition.org/medievales/ 8315 ; DOI : https://doi.org/10.4000/medievales.8315 
Katy Bernard

\section{La Chanson de la Croisade albigeoise}

Ce dossier thématique de la revue Médiévales est consacré à la Chanson de la Croisade albigeoise - la Canso - écrite en langue d'oc au $\mathrm{XIII}^{\mathrm{e}}$ siècle ${ }^{1}$. Composée de 9582 vers $^{2}$ répartis en 214 laisses, elle relate, ainsi que l'indique son titre, l'expédition croisée qui eut lieu principalement sur les terres des comtes de Toulouse et de leurs vassaux et voisins afin d'éradiquer l'hérésie dite « cathare » ou « albigeoise » qui s'y était développée. De ces faits historiques dont elle est contemporaine, la Chanson ne retranscrit que ceux qui eurent lieu entre 1208 et 1219. Elle s'ouvre sur les origines de la Croisade, avant les premiers faits d'armes de 1209, et s'achève par la chute de Marmande et une nouvelle marche des croisés vers Toulouse qui se prépare à soutenir un nouveau siège, après celui de 1217-1218. Dans cette œuvre, se dressent donc, au sein d'une multitude de personnages, les grandes figures historiques que furent le pape Innocent III qui appela à cette Croisade, son légat, Arnaud Amauri, qui en fut le premier chef spirituel, et Simon de Montfort qui de l'armée des barons croisés envoyée par le roi de France Philippe Auguste prit la tête après la reddition de Raymond Roger Trencavel, vicomte de Béziers et de Carcassonne, dont il obtint les terres par octroi de l'Église en 1209. Se lèvent également Raymond VI, comte de Toulouse, son fils, qui deviendra Raymond VII, et leurs vassaux, notamment le comte de Foix. On voit aussi, parmi d'autres figures saillantes, celle de Foulque de Marseille qui, ancien troubadour devenu évêque de Toulouse, s'allia à Simon de Montfort, et celle du prince Louis, fils de Philippe

1. L'édition utilisée dans ce volume est celle d'E. MARTin-CHABOt, La Chanson de la Croisade albigeoise, t. I-III, Paris, (1931-1961) 1960-1973. Le texte de la Chanson établi par E. Martin-Chabot est disponible en Livre de Poche : La Chanson de la Croisade albigeoise, traduction et adaptation de H. GoUgAud, préface de G. DUBY, introduction de M. ZINK, Paris, 1989 (Lettres gothiques).

2. Cf. La Chanson..., Introduction, t. I, p. XXXII. 
Auguste et futur Louis VIII qui prendra part directement aux combats des croisés après la mort de Simon de Montfort lors du siège de Toulouse en 1218. C'est alors, depuis 1216, le règne d'un autre pape, Honorius III. À ces figures et faits historiques et à d'autres encore qui ne sont pas cités ici, la Chanson offre - de diverses manières, par divers procédés - une envergure singulière, mythique; que ce soit au moment de sa création, à l'heure de sa redécouverte au $\mathrm{XIX}^{\mathrm{e}}$ siècle, ou encore aujourd'hui.

Outre le fait d'être contemporaine des événements qu'elle relate, la Chanson a pour autre caractéristique d'avoir été composée par deux auteurs.

Le premier, Guilhem de Tudela, Guillaume de Tudèle, est un clerc originaire de Navarre devenu, par ses services, chanoine du bourg Saint-Antonin. Il chante en faveur de la Croisade albigeoise, du moins originairement. Son protecteur est Baudouin, le frère cadet de Raymond VI, qui fit alliance avec Simon de Montfort. Son récit couvre les événements qui vont de 1208 à 1213. Sa composition s'arrête au moment de la préparation de la bataille de Muret. Guillaume de Tudèle inscrit sa chanson dans la lignée de la Canso d'Antioca, la Chanson d'Antioche, poème épique dont il a fait son modèle et qui lui donne ces laisses d'alexandrins que vient clore un hexasyllabe.

Le second auteur est resté anonyme et peu de choses sont sues de lui, si ce n'est, notamment, qu'il est très attaché à Toulouse et lié à ses comtes et à leurs vassaux dont, plus particulièrement, Roger Bernard (II) de Foix, le fils du comte de Foix, qui semble être un de ses mécènes. Si cet auteur anonyme inscrit son texte dans la continuité de celui de Guillaume de Tudèle - il reprend le texte de ce dernier exactement là où il l'a laissé et compose ainsi son récit des événements qui vont de 1213 à 1219 -, sa chanson à lui est, avec flamboyance, celle de la cause de Toulouse, de la contre-Croisade.

Les grands traits de ce portrait, que les contributions de ce volume et les références qu'elles contiennent permettront de compléter, suffisent à montrer combien la Chanson de la Croisade albigeoise est ce que nous appellerons une œuvre-carrefour. Côtoyant le genre de la chronique comme celui de la chanson épique, constituée de deux visions originairement opposées des événements qu'elle retranscrit, portée par deux intentions et deux styles très différents, cette œuvre réunit naturellement les dimensions historique, historiographique et littéraire. C'est dans cette optique que nous avons conçu, avec les différents contributeurs, l'architecture de ce dossier.

Avec les contributions de Sandrine Lavaud et de Philippe Martel, l'ensemble s'ouvre sur la dimension historiographique ( $\mathrm{XIX}^{\mathrm{e}}-\mathrm{XX}^{\mathrm{e}}$ siècles). Sandrine Lavaud fournit le cadre et le contexte dans lequel s'inscrit la redécouverte de la Chanson, tandis que Philippe Martel expose les circonstances et les conséquences de cette redécouverte à partir des premières mentions, éditions et analyses de l'œuvre. 
La contribution de Marjolaine Raguin conduit le lecteur dans la dimension historico-littéraire de cette Chanson, en la situant par rapport aux autres chansons de croisades occitanes et françaises afin de déterminer plus avant aussi bien son appartenance à une tradition (qui part de la Canso d'Antioca) que sa singularité.

Les trois dernières contributions, celle de Laurent Macé, celle de Frédéric Boutoulle et la nôtre, s'arrêtent au cœur de l'œuvre, s'attachant à différents stades et aspects du récit. Nous nous penchons sur le traitement singulier réservé au personnage de Simon de Montfort qui, de Guillaume de Tudèle à son Continuateur anonyme, prend l'envergure d'un héros tragique. Laurent Macé porte, quant à lui, son analyse sur l'importance que l'Anonyme accorde aux jeunes princes méridionaux que sont Raymond VII de Toulouse, Roger Bernard de Foix et Bernard de Comminges pour en faire les porteurs de l'espoir de leur lignage et des valeurs de leur société. La contribution de Frédéric Boutoulle, en écho à la fin de la Chanson, conclut l'ensemble par l'analyse du traitement du siège et de la prise de Marmande, qu'elle resitue dans son contexte historique.

À tous points de vue, la Chanson de la Croisade albigeoise - estil besoin de le dire ? - est une ouvre magistrale à laquelle nous nous réjouissons de pouvoir rendre hommage ici en si belle compagnie.

Nous remercions vivement les différents auteurs pour leur précieuse participation à ce dossier et les membres du comité de rédaction de la revue Médiévales pour avoir bien voulu nous en confier la direction ${ }^{3}$.

Katy Bernard - Université Bordeaux Montaigne, EA 4195 TELEM

3. Nos remerciements vont tout particulièrement à Nicolas Weill-Parot, qui en a assuré avec nous la coordination technique. 
